\title{
Vibrational spectroscopy of the sulphate mineral sturmanite from Kuruman manganese deposits, South Africa
}

\author{
Ray L. Frost ${ }^{\mathrm{a}, *}$, Ricardo Scholz ${ }^{\mathrm{b}}$, Andrés López ${ }^{\mathrm{a}}$, Yunfei Xi ${ }^{\mathrm{a}}$, Cristiano Lana ${ }^{\mathrm{b}}$

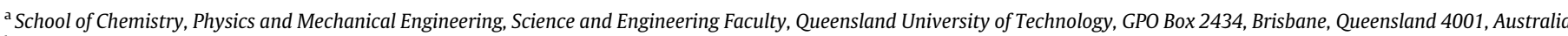 \\ ${ }^{\mathrm{b}}$ Geology Department, School of Mines, Federal University of Ouro Preto, Campus Morro do Cruzeiro, Ouro Preto, MG 35400-00, Brazil
}

\section{H I G H L I G H T S}

- We have analysed the mineral sturmanite.

- Formula $\mathrm{Ca}_{6}(\mathrm{Fe}, \mathrm{Al}$,

$\mathrm{Mn})_{2}\left(\mathrm{SO}_{4}\right)_{2}\left(\mathrm{~B}(\mathrm{OH})_{4}\right)(\mathrm{OH})_{12} \cdot 26 \mathrm{H}_{2} \mathrm{O}$.

- The mineral is unusual as it contains both sulphate and hydroxyborate anions.

- Chemical analysis shows a

homogeneous phase, composed by $\mathrm{Ca}, \mathrm{Fe}, \mathrm{Mn}, \mathrm{S}, \mathrm{Al}$ and $\mathrm{Si}$.

- Bands attributed to sulphate and hydroxyborate anions are identified.

\section{A R T I C L E I N F O}

\section{Article history:}

Received 18 February 2014

Received in revised form 15 April 2014

Accepted 22 April 2014

Available online 30 April 2014

\section{Keywords}

Raman spectroscopy

Sturmanite

Borate

Kuruman

Infrared spectroscopy

Thermal analysis

\section{G R A P H I C A L A B S T R A C T}

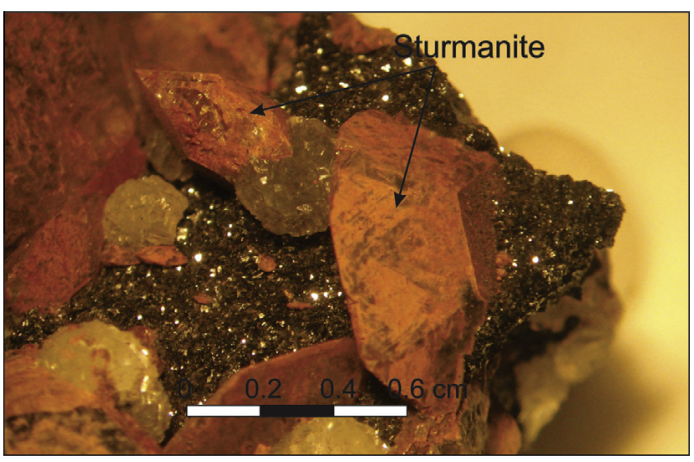

\begin{abstract}
A B S T R A C T
The mineral sturmanite is a hydrated calcium iron aluminium manganese sulphate tetrahydroxoborate hydroxide of formula $\mathrm{Ca}_{6}(\mathrm{Fe}, \mathrm{Al}, \mathrm{Mn})_{2}\left(\mathrm{SO}_{4}\right)_{2}\left(\mathrm{~B}(\mathrm{OH})_{4}\right)(\mathrm{OH})_{12} \cdot 26 \mathrm{H}_{2} \mathrm{O}$. We have studied the mineral sturmanite using a number of techniques, including SEM with EPMA and vibrational spectroscopy. Chemical analysis shows a homogeneous phase, composed by $\mathrm{Ca}, \mathrm{Fe}, \mathrm{Mn}, \mathrm{S}, \mathrm{Al}$ and $\mathrm{Si}$. B is not determined in this EPMA technique. An intense Raman band at $990 \mathrm{~cm}^{-1}$ is assigned to the $\mathrm{SO}_{4}^{2-}$ symmetric stretching mode. Raman spectroscopy identifies multiple sulphate symmetric stretching modes in line with the three sulphate crystallographically different sites. Raman spectroscopy also identifies a band at $1069 \mathrm{~cm}^{-1}$ which may be attributed to a carbonate symmetric stretching mode, indicating the presence of thaumasite. Infrared spectra display two bands at 1080 and $1107 \mathrm{~cm}^{-1}$ assigned to the $\mathrm{SO}_{4}^{2-}$ antisymmetric stretching modes. The observation of multiple bands in this $v_{4}$ spectral region offers evidence for the reduction in symmetry of the sulphate anion from $T_{\mathrm{d}}$ to $C_{2 \mathrm{v}}$ or even lower symmetry. The Raman band at $3622 \mathrm{~cm}^{-1}$ is assigned to the $\mathrm{OH}$ unit stretching vibration and the broad feature at around $3479 \mathrm{~cm}^{-1}$ to water stretching bands. Infrared spectroscopy shows a set of broad overlapping bands in the $\mathrm{OH}$ stretching region. Vibrational spectroscopy enables an assessment of the molecular structure of sturmanite to be made.
\end{abstract}

(c) 2014 Elsevier B.V. All rights reserved.

\section{Introduction}

The mineral sturmanite is a hydrated calcium iron aluminium manganese sulphate tetrahydroxoborate hydroxide of formula

\footnotetext{
* Corresponding author. Tel.: +61 73138 2407; fax: +61 731381804 .

E-mail address: r.frost@qut.edu.au (R.L. Frost).
}

$\mathrm{Ca}_{6}(\mathrm{Fe}, \mathrm{Al}, \mathrm{Mn})_{2}\left(\mathrm{SO}_{4}\right)_{2}\left(\mathrm{~B}(\mathrm{OH})_{4}\right)(\mathrm{OH})_{12} \cdot 26 \mathrm{H}_{2} \mathrm{O}$ [1]. Some mineral references list the sturmanite chemistry as $\mathrm{Ca}_{6} \mathrm{Fe}_{2}\left(\mathrm{SO}_{4}\right)_{2}\left(\mathrm{~B}(\mathrm{OH})_{4}\right)$ $(\mathrm{OH})_{12} \cdot 26 \mathrm{H}_{2} \mathrm{O}$ without the manganese and aluminium which substitute for iron to an appreciable extent [1].

Sturmanite forms as a precipitate from hydrothermal solutions. The mineral is a member of the ettringite mineral group [2,3] The mineral is also closely related to charlesite $\mathrm{Ca}_{6}(\mathrm{Al}, \mathrm{Si})_{2}$ 
$\left(\mathrm{SO}_{4}\right)_{2} \mathrm{~B}(\mathrm{OH})_{4}(\mathrm{OH}, \mathrm{O})_{12} \cdot 26\left(\mathrm{H}_{2} \mathrm{O}\right)$. Ettringite belongs to the homonymous group that also includes thaumasite, sturmanite, charlesite, buryatite, jouravskite, bentorite, hielschetite, kottenheimite, micheelsenite and carraraite. Both sturmanite and ettringite are

Table 1

Chemical composition of eosphorite from pegmatites from Minas Gerais; $\mathrm{H}_{2} \mathrm{O}$ calculated by thermogravimetric analysis and values given in mass fraction \%. The stoichiometric composition of eosphorite and childrenite is also shown.

\begin{tabular}{lrll}
\hline Constituent & \% Mass & $\begin{array}{l}\text { Number of cations } \\
\text { per unit cell }\end{array}$ & Probe standard \\
\hline $\mathrm{CaO}$ & 24.91 & 5.62 & $\mathrm{Ca}_{2} \mathrm{P}_{2} \mathrm{O}_{7}$ \\
$\mathrm{Fe}_{2} \mathrm{O}_{3}$ & 9.23 & 1.46 & Pyrite \\
$\mathrm{MnO}_{\mathrm{SO}_{3}}$ & 2.00 & 0.36 & Rhodonite \\
$\mathrm{B}_{2} \mathrm{O}_{3}$ & 13.23 & 2.03 & Pyrite \\
$\mathrm{Na}_{2} \mathrm{O}$ & 2.75 & 0.99 & Calculated by stoichiometry \\
$\mathrm{MgO}$ & 0.01 & 0.00 & Albite 100 \\
$\mathrm{Al}_{2} \mathrm{O}_{3}$ & 0.01 & 0.00 & MgO \\
$\mathrm{SiO}_{2}$ & 0.07 & 0.01 & Albite 100 \\
$\mathrm{H}_{2} \mathrm{O}$ & 0.09 & 0.02 & Albite 100 \\
$\mathrm{Total}$ & 46.97 & & Calculated by stoichiometry \\
\hline
\end{tabular}

found in the manganese Kalahari fields primarily from N'Chwaning I and II mines.

Sturmanite also forms well shaped crystals which are often a bright yellow colour, making the mineral an essential item for mineral collectors. A picture of sturmanite is given in the graphical abstract (used with the kind permission of M\&D minerals). Sturmanite usually forms long hexagonal crystals, as may be seen in the picture. The chemistry of sturmanite is most interesting. In comparison with the mineral ettringite $\mathrm{Ca}_{6} \mathrm{Al}_{2}(\mathrm{OH})_{12}\left(\mathrm{SO}_{4}\right)_{3} \cdot 26 \mathrm{H}_{2} \mathrm{O}$ [3], one sulphate unit has been replaced with tetrahydroxoborate, $\mathrm{B}(\mathrm{OH})_{4}$. The mineral is predominantly made up of water with four out of every five atoms in this mineral is either a part of a water molecule or an hydroxide. Sturmanite is trigonal, $P 31 c, Z=2$, with a 11.188(9) $\AA$, $c$ 21.91(7) $\AA$, and $V$ 2375.1(5) $\AA^{3}$. According to Pushcharovsky et al. [4], the structure of sturmanite consists of two coaxial elements parallel to [001] and is the most distinctive features of sturmanite. The main one is a column of polyhedra formed by Fe-octahedra and Ca-polyhedra [4]. The $\mathrm{Fe}(\mathrm{OH})_{6}$ octahedra are located along the three-fold axes that pass through the origin of the cell. These are linked to three VIIICa-polyhedra, located around the three-fold axes, in between the $\mathrm{Fe}(\mathrm{OH})_{6}$ octahedra [4]. The second structural element parallel to [001] (a)

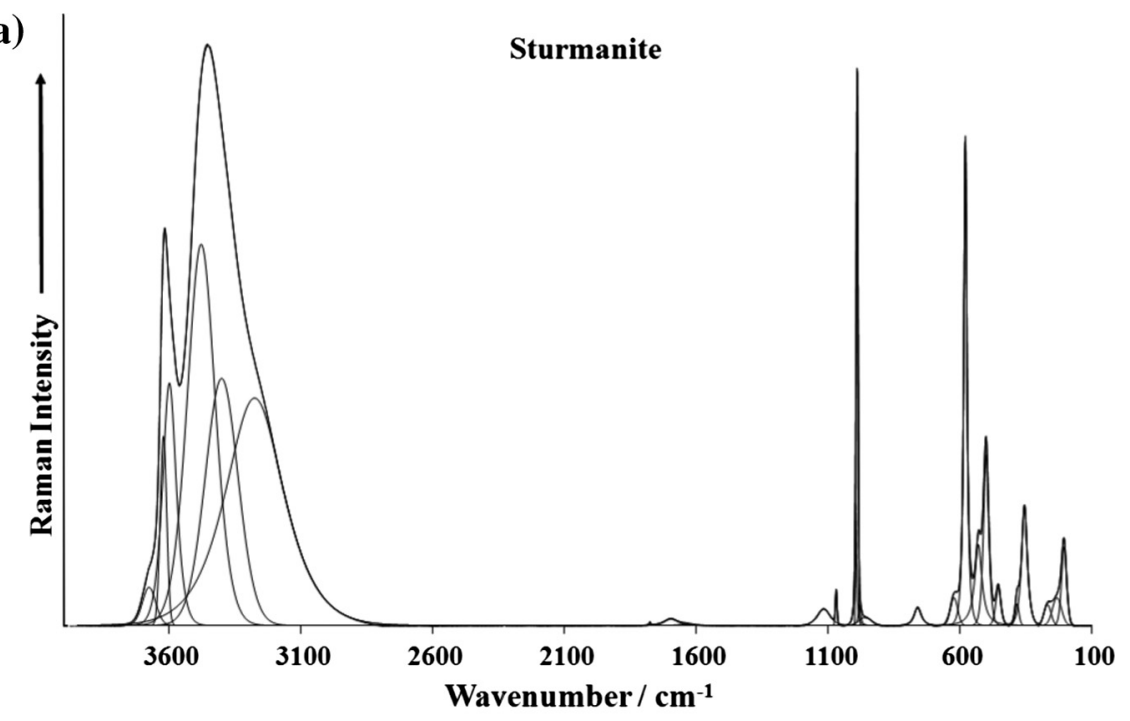

(b)

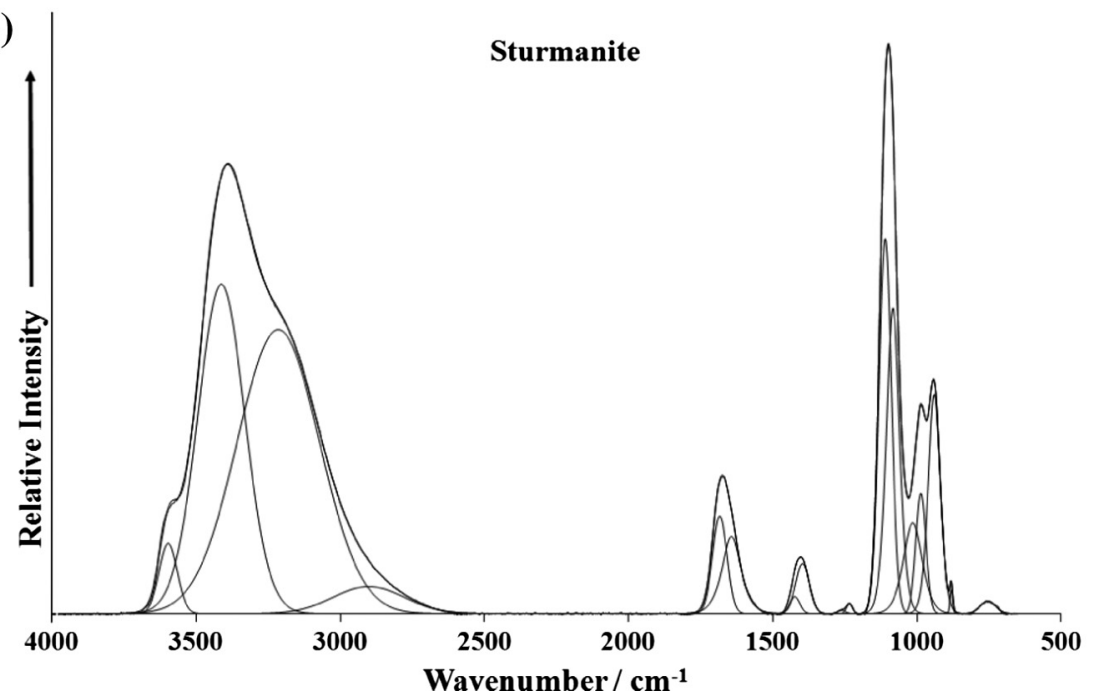

Fig. 1. (a) Raman spectrum of sturmanite over the $100-4000 \mathrm{~cm}^{-1}$ spectral range (upper spectrum) and (b) infrared spectrum of sturmanite over the $500-4000 \mathrm{~cm}^{-1}$ spectral range (lower spectrum). 
contains $\left[\mathrm{SO}_{4}\right]$ and $\mathrm{B}(\mathrm{OH})_{4}$ tetrahedra. According to Pushcharovsky et al. [4] both structural modules are linked to each other by a complex system of hydrogen bonds.

Raman spectroscopy has proven most useful for the study of mineral structure [5-8]. Vibrational spectroscopy is very important for the study of Mn containing minerals [3,9]. The objective of this research is to analyse the Raman and infrared spectra of sturmanite and to relate the spectra to the mineral structure.

\section{Experimental}

\section{Samples description and preparation}

The sturmanite sample studied in this work forms part of the collection of the Geology Department of the Federal University of Ouro Preto, Minas Gerais, Brazil, with sample code SAA-170. The mineral originated from Black Rock mine, Kalahari, RSA.

The sample was gently crushed and the associated minerals were removed under a stereomicroscope Leica MZ4. The sturmanite studied in this work occurs as single crystals with prismatic hexagonal form up to $5 \mathrm{~mm}$. Scanning electron microscopy (SEM) in the EDS mode was applied to support the mineral characterisation.
Electron probe micro-analysis (EPMA)

The quantitative chemical analysis of sturmanite crystals fragment was carried out using EPMA, with a Jeol JXA8900R spectrometer from the Physics Department of the Federal University of Minas Gerais, Belo Horizonte. For each selected element. An appropriate standard was used as listed in Table 1 . The electron probe microanalysis in the WDS (wavelength dispersive spectrometer) mode was obtained at $15 \mathrm{kV}$ accelerating voltage and beam current of $10 \mathrm{nA}$. Chemical formula was calculated on the basis of 49 oxygen atoms.

\section{Raman microprobe spectroscopy}

Crystals of sturmanite were placed on a polished metal surface on the stage of an Olympus BHSM microscope, which is equipped with $10 \times, 20 \times$, and $50 \times$ objectives. The microscope is part of a Renishaw 1000 Raman microscope system, which also includes a monochromator, a filter system and a CCD detector (1024 pixels). The Raman spectra were excited by a Spectra-Physics model 127 He-Ne laser producing highly polarised light at $633 \mathrm{~nm}$ and collected at a nominal resolution of $2 \mathrm{~cm}^{-1}$ and a precision of $\pm 1 \mathrm{~cm}^{-1}$ in the range between 100 and $4000 \mathrm{~cm}^{-1}$. The Raman (a)

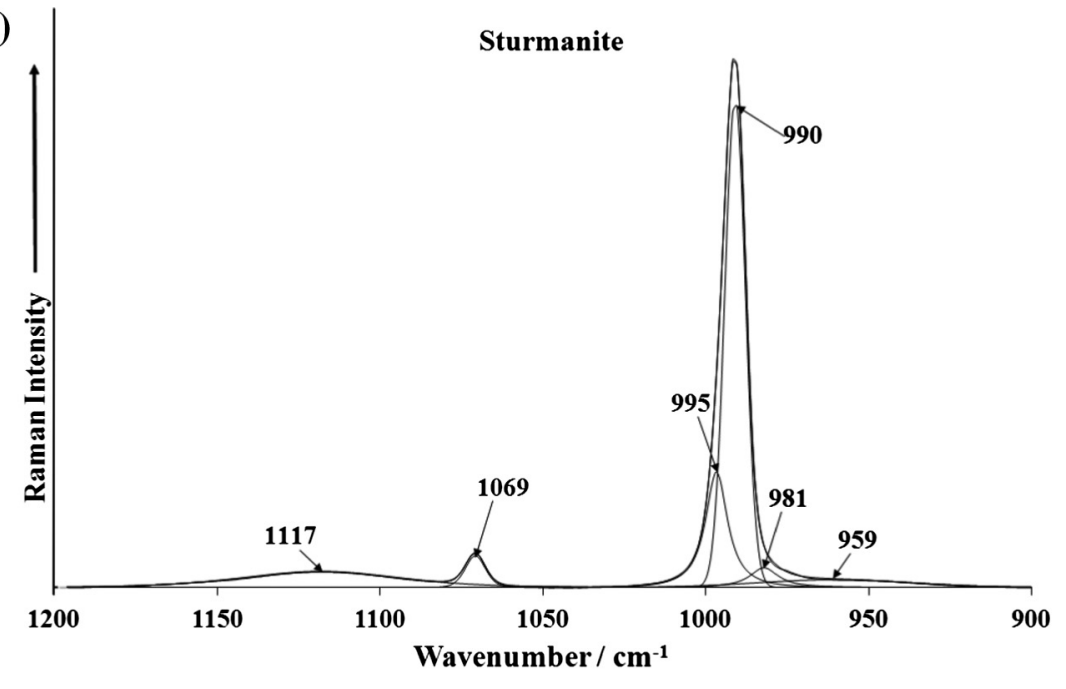

(b)

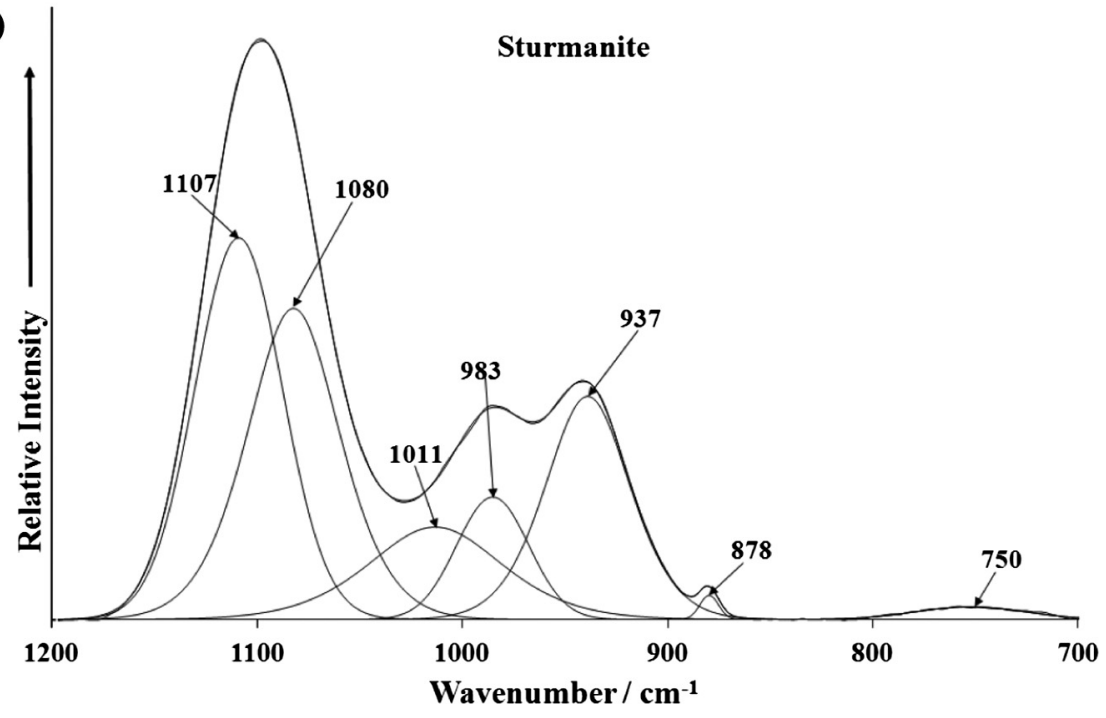

Fig. 2. (a) Raman spectrum of sturmanite over the $800-1400 \mathrm{~cm}^{-1}$ spectral range (upper spectrum) and (b) infrared spectrum of sturmanite over the $500-1300 \mathrm{~cm}^{-1}$ spectral range (lower spectrum). 
spectrum of at least 10 crystals was collected to ensure the consistency of the spectra. Repeated acquisitions on the crystals using the highest magnification $(50 \times)$ were accumulated to improve the signal to noise ratio of the spectra. Raman Spectra were calibrated using the $520.5 \mathrm{~cm}^{-1}$ line of a silicon wafer.

\section{Infrared spectroscopy}

Infrared spectra were obtained using a Nicolet Nexus 870 FTIR spectrometer with a smart endurance single bounce diamond ATR cell. Spectra over the $4000-525 \mathrm{~cm}^{-1}$ range were obtained by the co-addition of 128 scans with a resolution of $4 \mathrm{~cm}^{-1}$ and a mirror velocity of $0.6329 \mathrm{~cm} / \mathrm{s}$. Spectra were co-added to improve the signal to noise ratio.

Spectral manipulation such as baseline correction/adjustment and smoothing were performed using the Spectracalc software package GRAMS (Galactic Industries Corporation, NH, USA). Band component analysis was undertaken using the Jandel 'Peakfit' software package that enabled the type of fitting function to be selected and allows specific parameters to be fixed or varied accordingly. Band fitting was done using a Lorentzian-Gaussian cross-product function with the minimum number of component bands used for the fitting process. The Lorentzian-Gaussian ratio was maintained at values greater than 0.7 and fitting was undertaken until reproducible results were obtained with squared correlations of $r^{2}$ greater than 0.995 .

\section{Results and discussion}

\section{Mineral characterisation}

Chemical analysis of sturmanite studied in this work is presented in Table 1 . The image shows an sturmanite crystal aggregate as provided in the graphical abstract. Individual crystals up to $30 \mu \mathrm{m}$ in length are observed. Crystals show hexagonal prismatic habitus. Qualitative chemical analysis shows a homogeneous phase, composed by $\mathrm{Ca}, \mathrm{Al}$ and $\mathrm{Si}$. Carbon was also observed and occurs due to $C$ coating. Boron was not detected as the atomic number is low.

\section{Spectroscopy}

\section{Background}

Sulphate typically is a tetrahedral oxyanion with Raman bands at $981\left(v_{1}\right), 451\left(v_{2}\right), 1104\left(v_{3}\right)$ and $613\left(v_{4}\right) \mathrm{cm}^{-1}$ [10]. Some sulphates have their symmetry reduced through acting as monodentate and bidentate ligands [10]. In the case of bidentate behaviour both bridging and chelating ligands are known. This reduction in (a)

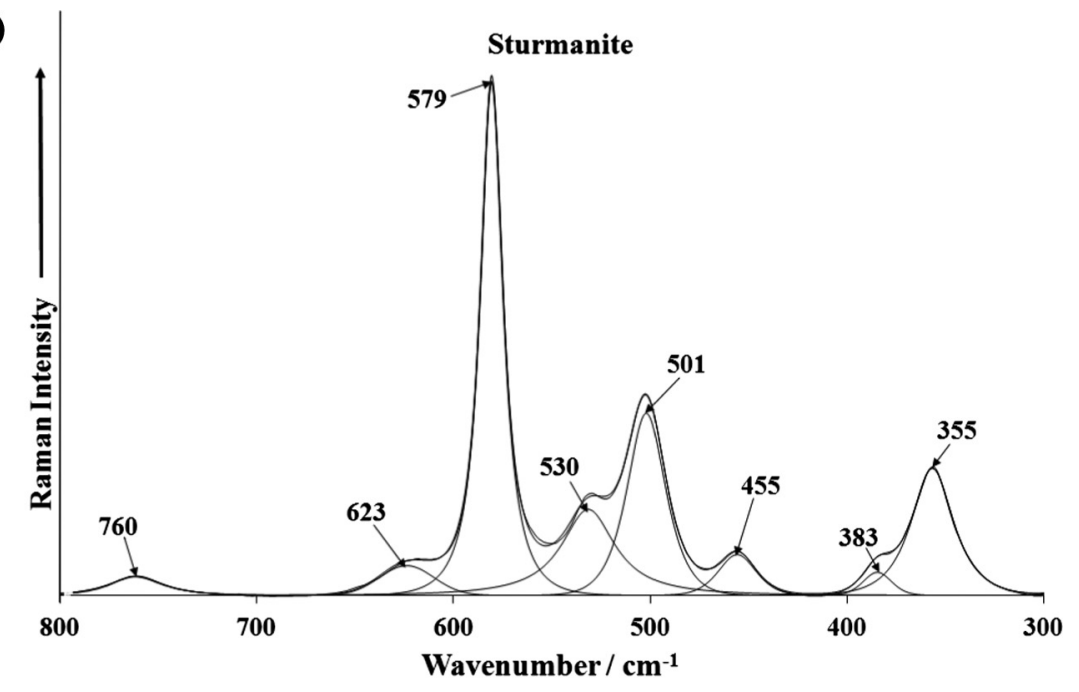

(b)

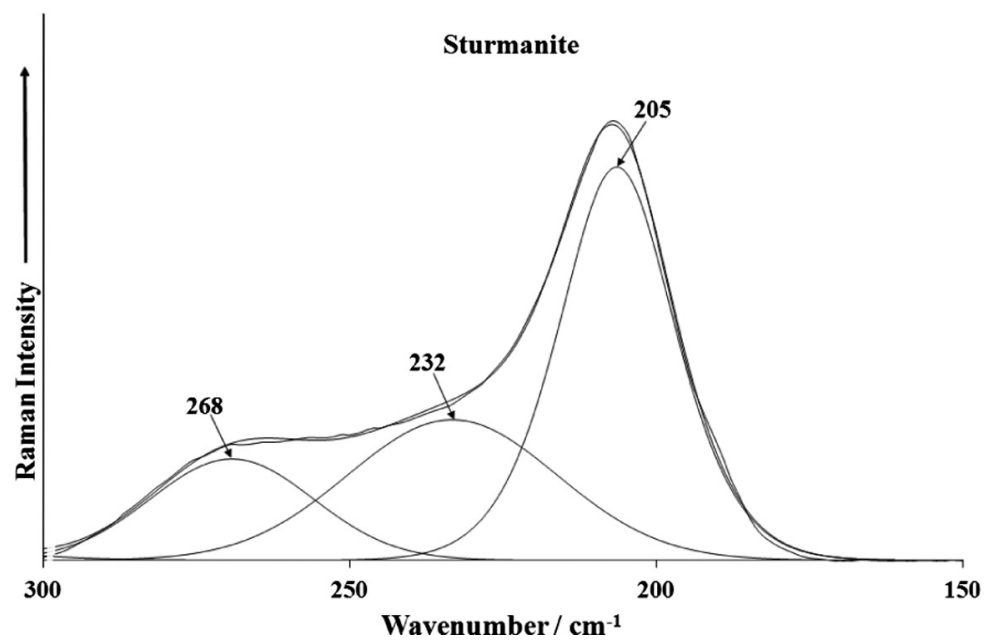

Fig. 3. (a) Raman spectrum of sturmanite over the $300-800 \mathrm{~cm}^{-1}$ spectral range (upper spectrum) and (b) Raman spectrum of sturmanite over the $100-300 \mathrm{~cm}^{-1}$ spectral range (lower spectrum). 
symmetry is observed by the splitting of the $v_{3}$ and $v_{4}$ into two components under $C_{3 \mathrm{v}}$ symmetry and 3 components under $C_{2 \mathrm{v}}$ symmetry. The vibrational spectra of ettringite have been reported [3]. The Raman spectroscopy of the aqueous sulphate tetrahedral oxyanion yields the symmetric stretching $\left(v_{1}\right)$ vibration at $981 \mathrm{~cm}^{-1}$, the in-plane bending $\left(v_{2}\right)$ mode at $451 \mathrm{~cm}^{-1}$, the antisymmetric stretching $\left(v_{3}\right)$ mode at $1104 \mathrm{~cm}^{-1}$ and the out-of-plane bending $\left(v_{4}\right)$ mode at $613 \mathrm{~cm}^{-1}$ [11]. Ross reports the interpretation of the infrared spectra for potassium alum as $v_{1}, 981 \mathrm{~cm}^{-1}$; $v_{2}, 465 \mathrm{~cm}^{-1} ; v_{3}, 1200,1105 \mathrm{~cm}^{-1} ; v_{4}, 618$ and $600 \mathrm{~cm}^{-1}$ [12]. Water stretching modes were reported at 3400 and $3000 \mathrm{~cm}^{-1}$, bending modes at $1645 \mathrm{~cm}^{-1}$, and librational modes at 930 and $700 \mathrm{~cm}^{-1}$ [13]. The Raman spectrum of the mineral chalcanthite shows a single symmetric stretching mode at $984.7 \mathrm{~cm}^{-1}$. Two $v_{2}$ modes are observed at 463 and $445 \mathrm{~cm}^{-1}$ and three $v_{3}$ modes at 1173,1146 and $1100 \mathrm{~cm}^{-1}$. The $v_{4}$ mode is observed as a single band at $610 \mathrm{~cm}^{-1}$. A complex set of overlapping bands is observed in the low wavenumber region at 257, 244, 210, 136 and $126 \mathrm{~cm}^{-1}$. Recently, Raman spectra of four basic copper sulphate minerals, namely antlerite, brochiantite, posnjakite and langite, were published [14]. The SO symmetric stretching modes for the four basic copper sulphate minerals are observed at 985, 990, 972 and $974 \mathrm{~cm}^{-1}$. Only the mineral brochantite showed a single band in this region. Multiple bands were observed for these minerals in the antisymmetric stretching region.

\section{Vibrational spectroscopy}

The Raman spectrum of sturmanite over the complete measured wavenumbers is displayed in Fig. 1a. This figure shows the position of the Raman bands and their relative intensities and also provides an indication of the sharpness of these bands. Large parts of the spectrum are noted where little or no intensity is found. Therefore, the spectra are subdivided into sections based upon the differing vibrations being studied. The infrared spectrum of sturmanite over the $500-4000 \mathrm{~cm}^{-1}$ spectral range is reported in Fig. $1 \mathrm{~b}$. This figure shows the position and relative intensities of the infrared active sturmanite bands. The spectra are subdivided into sections as is convenient based upon the vibrations being studied. A comparison may be made between the Raman and infrared spectra of sturmanite.

The Raman spectrum of sturmanite over the $900-1200 \mathrm{~cm}^{-1}$ spectral range is displayed in Fig. 2a. This spectral region is the region of the sulphate symmetric stretching modes. The spectrum is dominated by an intense Raman band at $990 \mathrm{~cm}^{-1}$. This band at $990 \mathrm{~cm}^{-1}$ is assigned to the $\mathrm{SO}_{4}^{2-} v_{1}$ symmetric stretching mode. The position of this band is in agreement with previously published data [15]. Two low intensity shoulders to this band are observed at 981 and $995 \mathrm{~cm}^{-1}$. In addition, Raman bands are observed at 1069 (sharp) and 1117 (very broad). These bands are attributed to the $\mathrm{SO}_{4}^{2-} v_{3}$ antisymmetric stretching mode.
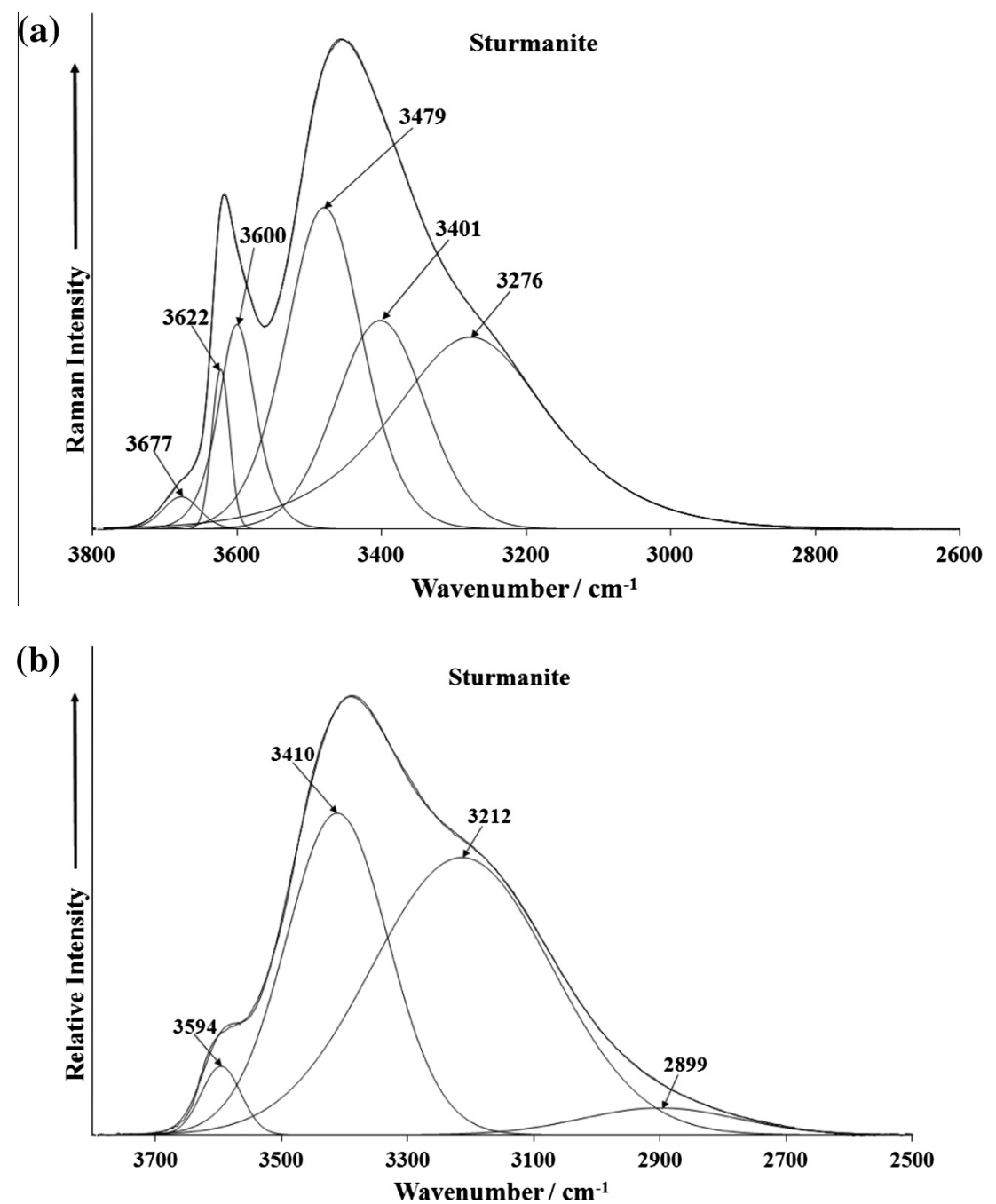

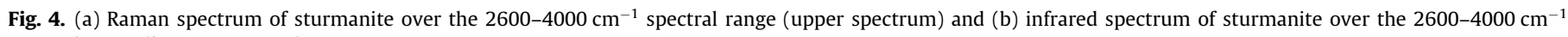
spectral range (lower spectrum). 
According to Myneni [16], the $\mathrm{SO}_{4}^{2-}$ polyhedra of the channels in sturmanite are present in three crystallographically different sites and exhibit weakly split S-O antisymmetric stretching vibrations at $1136 \mathrm{~cm}^{-1}$ (with several components) and symmetric stretch at 1016,1008 , and $989 \mathrm{~cm}^{-1}$. The observation of three symmetric stretching bands in this work, fits well with the concept of three different non-equivalent sulphate units in the sturmanite structure. The band at $1069 \mathrm{~cm}^{-1}$ looks very much like a carbonate stretching mode. It is possible that the mineral being studied is a solid solution between sturmanite and thaumasite $\mathrm{Ca}_{3}\left(\mathrm{SO}_{4}\right)$ $\left[\mathrm{Si}(\mathrm{OH})_{6}\right] \mathrm{CO}_{3} \cdot 12 \mathrm{H}_{2} \mathrm{O}$. Thus, the presence of this latter mineral in the solid solution would give rise to the carbonate bands.

The infrared spectrum of sturmanite over the $700-1200 \mathrm{~cm}^{-1}$ spectral range is shown in Fig. 2b. Strong infrared bands are observed at 1080 and $1107 \mathrm{~cm}^{-1}$ and are assigned to the $\mathrm{SO}_{4}^{2-} v_{3}$ antisymmetric stretching mode. These bands are of very low intensity in the Raman spectrum. The low intensity infrared band at $983 \mathrm{~cm}^{-1}$ is attributed to the $\mathrm{SO}_{4}^{2-} v_{1}$ symmetric stretching mode. This band is the equivalent of the Raman band observed at $990 \mathrm{~cm}^{-1}$. The infrared bands of sturmanite at 878 and $937 \mathrm{~cm}^{-1}$ may be associated with water librational bands.

The Raman spectra of sturmanite over the $300-800 \mathrm{~cm}^{-1} \mathrm{spec}$ tral range and over the $150-300 \mathrm{~cm}^{-1}$ spectral range are shown in Fig. 3. A series of Raman bands are observed at 501, 530, 579 and $623 \mathrm{~cm}^{-1}$. These bands are assigned to the $v_{4}\left(\mathrm{SO}_{4}\right)^{2-}$ bending modes. Renaudin et al. [15] found a Raman band at $549 \mathrm{~cm}^{-1}$ for a synthetic ettringite analogue and attributed this band to an $\mathrm{Al}(\mathrm{OH})_{6}$ vibration. We found a Raman band at $530 \mathrm{~cm}^{-1}$. The observation of multiple bands in this $v_{4}$ spectral region offers evidence for the reduction in symmetry of the sulphate anion from $T_{\mathrm{d}}$ to $C_{2 v}$ or even lower symmetry. The Raman band at $760 \mathrm{~cm}^{-1}$ is attributed to a hydroxyl deformation mode associated with $\mathrm{AlOH}$ units. It is likely that the infrared bands at 750 and $878 \mathrm{~cm}^{-1}$ are due also to this vibrational unit. The Raman band at $455 \mathrm{~cm}^{-1}$ is ascribed to the $v_{2}\left(\mathrm{SO}_{4}\right)^{2-}$ bending modes. Renaudin et al. [15] found a band at $451 \mathrm{~cm}^{-1}$ for a synthetic ettringite analogue and assigned this band to a $v_{2}$ sulphate vibration. The band at $355 \mathrm{~cm}^{-1}$ with a shoulder band at $383 \mathrm{~cm}^{-1}$ is attributed to a $\mathrm{CaO}$ and other $\mathrm{M}-\mathrm{O}$ stretching vibrations. In the far low wavenumber region, a broad spectral feature is observed which may be resolved into component bands at 205, 232 and $268 \mathrm{~cm}^{-1}$. These bands are simply described as lattice vibrations.

The Raman spectrum of sturmanite over the $2600-3800 \mathrm{~cm}^{-1}$ spectral range is illustrated in Fig. 4a. The spectrum shows two features: bands at 3600 and $3622 \mathrm{~cm}^{-1}$ and a broad feature at around $3479 \mathrm{~cm}^{-1}$ which may be resolved into component bands at 3276 , 3401 and $3479 \mathrm{~cm}^{-1}$. The first two bands at 3600 and $3622 \mathrm{~cm}^{-1}$ is assigned to the $\mathrm{OH}$ stretching vibration of the $\mathrm{OH}$ units. It is not unexpected to observe $\mathrm{OH}$ stretching vibrations as the mineral contains $\mathrm{B}(\mathrm{OH})_{4}$ units. It is likely that these two peaks are due to
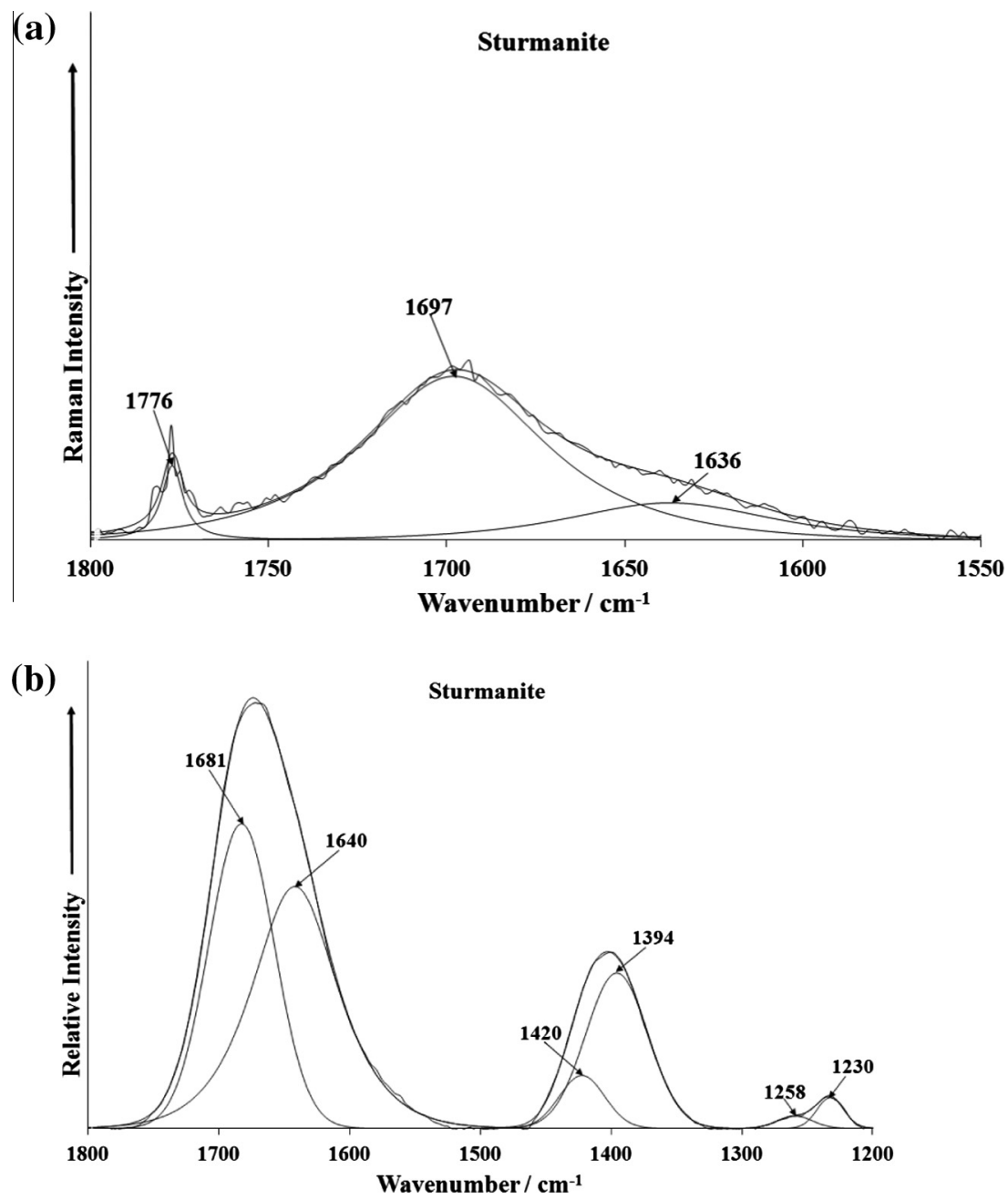

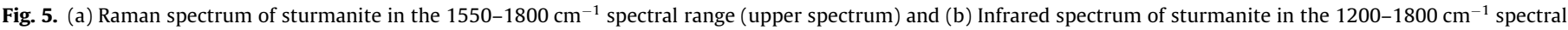
range (lower spectrum). 
the two isotopes of boron. The nominal resolution of the Raman spectrometer is of the order of $2 \mathrm{~cm}^{-1}$ and as such is sufficient enough to identify separate bands for the stretching bands of the two boron isotopes. The two reduced masses for a pure $\mathrm{B}-\mathrm{O}$ stretching mode would be $(10 \times 16) /(10+16)=6.154$ for $10-B$ and $(11 \times 16) /(11+16)=6.518$ for $11-B$. The wavenumber is inversely proportional to square root of reduced mass; so the isotopic wavenumber ratio should be the $\operatorname{sqrt}(6.518 / 6.154)=1.03$. $10-\mathrm{B}$ is about $20 \%$ of natural boron, so a mode that is mostly B-O stretching and that includes significant motion of the $\mathrm{B}$ atom (not a breathing mode of a $\mathrm{BO}_{3}$ trigonal planar unit or a $\mathrm{BO}_{4}$ tetrahedral unit) should show a large peak for 11-B and a smaller peak at higher wavenumber for 10-B.

The broad feature centred upon $3479 \mathrm{~cm}^{-1}$ is attributed to water stretching vibrations. Renaudin et al. [15] observed the $\mathrm{OH}$ stretching vibration at $3638 \mathrm{~cm}^{-1}$ for ettringite. These researchers found the water band at $3440 \mathrm{~cm}^{-1}$ and showed the band was very broad. The infrared spectrum of sturmanite over the 2500$3800 \mathrm{~cm}^{-1}$ spectral range is reported in Fig. 4b. The spectrum is very broad. Infrared bands may be resolved at 3212, 3410 and $3594 \mathrm{~cm}^{-1}$ with a broad tail at $2899 \mathrm{~cm}^{-1}$. The first two bands are ascribed to water stretching bands. The infrared band at $3594 \mathrm{~cm}^{-1}$ is assigned to the stretching vibration of $\mathrm{OH}$ units from the $\mathrm{B}(\mathrm{OH})_{4}$ units.

The Raman spectrum of sturmanite over the $1550-1800 \mathrm{~cm}^{-1}$ spectral range is illustrated in Fig. 5a. As for the Raman spectrum of the $\mathrm{OH}$ stretching region of sturmanite, the bands in this spectral region are very broad. A broad Raman band is noted at $1697 \mathrm{~cm}^{-1}$ with a tail at $1636 \mathrm{~cm}^{-1}$. These bands are attributed to water bending modes. These bands are also observed in the infrared spectrum of sturmanite shown in Fig. 5b. Infrared bands are observed at 1640 and $1681 \mathrm{~cm}^{-1}$ and are assigned to water bending vibrations. The two infrared bands at 1394 and $1420 \mathrm{~cm}^{-1}$ are due to the presence of the $\mathrm{B}(\mathrm{OH})_{4}$ units in the sturmanite structure, These bands are assigned to the antisymmetric stretching of trigonal boron. A second possible assignment is to the $\mathrm{OH}$ in-plane bending of the $\mathrm{OH}$ units of $\mathrm{B}(\mathrm{OH})_{4}$ units although the two infrared bands at 1230 and $1258 \mathrm{~cm}^{-1}$ are more likely candidates for this vibrational mode.

\section{Conclusions}

We have attempted to study the mineral sturmanite a hydrated calcium iron aluminium manganese sulphate tetrahydroxoborate hydroxide of formula $\mathrm{Ca}_{6}(\mathrm{Fe}, \mathrm{Al}, \mathrm{Mn})_{2}\left(\mathrm{SO}_{4}\right)_{2}\left(\mathrm{~B}(\mathrm{OH})_{4}\right)(\mathrm{OH})_{12} \cdot 26 \mathrm{H}_{2} \mathrm{O}$ found in the manganese Kalahari fields primarily from N'Chwaning I and II mines. Chemical analysis shows a homogeneous phase, composed by $\mathrm{Ca}, \mathrm{Al}$ and $\mathrm{Si}$. The mineral contains boron which is not detected by the EDX technique. The mineral sturmanite may be compared with related sulphate mineral ettringite.

In the structure of sturmanite, one of the sulphate ion groups has been replaced by the unusual ion group, tetrahydroxoborate, $\mathrm{B}(\mathrm{OH}) 4$ with a negative one charge. The minerals sturmanite and ettringite occur in the same mineral localities and are not easily or readily distinguished.

Raman and infrared bands which are attributable to $\mathrm{SO}_{4}^{2-}$ stretching and bending modes are observed. The intense Raman band at $990 \mathrm{~cm}^{-1}$ is assigned to the $\mathrm{SO}_{4}^{2-}$ symmetric stretching mode. It could be expected that Raman and infrared bands which are attributable to the $\mathrm{B}(\mathrm{OH})_{4}$ units would be observed. For whatever reason, the bands are not obvious. One possibility is that the bands are under the envelope of the sulphate bands. The infrared bands observed at $1230,1258,1394$ and $1420 \mathrm{~cm}^{-1}$ are due to $\mathrm{BOH}$ out of plane bending modes. Intense Raman bands at 3600 and $3622 \mathrm{~cm}^{-1}$ are assigned to the stretching vibrations of the $\mathrm{B}(\mathrm{OH})_{4}$ units. Raman spectroscopy identifies some selected bands which are attributed to the presence of boron as $\mathrm{B}(\mathrm{OH})_{4}^{-}$.

\section{Acknowledgements}

The financial and infra-structure support of the Discipline of Nanotechnology and Molecular Science, Science and Engineering Faculty of the Queensland University of Technology, is gratefully acknowledged. The Australian Research Council (ARC) is thanked for funding the instrumentation. The authors would like to acknowledge the Center of Microscopy at the Universidade Federal de Minas Gerais (http://www.microscopia.ufmg.br) for providing the equipment and technical support for experiments involving electron microscopy. C. Lana thanks to CNPq - Conselho Nacional de Desenvolvimento Científico e Tecnológico (Grant No. 402852/ 2012-5).

\section{References}

[1] D.R. Peacor, P.J. Dunn, M. Duggan, Can. Min. 21 (1983) 705-709.

[2] S.M. Antao, M.J. Duane, I. Hassan, Can. Min. 40 (2002) 1403-1409.

[3] R.L. Frost, A. Lopez, Y. Xi, R. Scholz, G.M. da Costa, R.M.F. Lima, A. Granja, Vibr. Spectrosc. 68 (2013) 266-271.

[4] D.Y. Pushcharovsky, Y.S. Lebedeva, N.V. Zubkova, M. Pasero, M. Bellezza, S. Merlino, N.V. Chukanov, Can. Min. 42 (2004) 723-729.

[5] R.L. Frost, Y. Xi, Spectrochim. Acta A117 (2014) 428-433.

[6] R.L. Frost, R. Scholz, A. Lopez, Y. Xi, L.M. Graca, J. Mol. Struct. 1059 (2014) 20 26.

[7] R.L. Frost, R. Scholz, A. Lopez, F.L. Theiss, Spectrochim. Acta Part A 127 (2014) 349-354.

[8] R.L. Frost, R. Scholz, A. Lopes, Y. Xi, Z.Z. Gobac, C.d.C. Lana, Spectrochim. Acta Part A 116 (2013) 491-496.

[9] S. Lakshmi Reddy, K. Padma Suvarna, G. Udayabhaska Reddy, T. Endo, R.L. Frost, Spectrochim. Acta A117 (2014) 270-275.

[10] R.L. Frost, J.T. Kloprogge, P.A. Williams, P. Leverett, J. Raman Spectrosc. 31 (2000) 1083-1087.

[11] R.L. Frost, P.A. Williams, W. Martens, J.T. Kloprogge, P. Leverett, J. Raman Spectrosc. 33 (2002) 260-263.

[12] S.D. Ross, in: V.C. Farmer (Ed.), The Infrared Spectra of Minerals, The Mineralogical Society, London, 1974, p. 423 (Chapter 18).

[13] S.D. Ross, Inorganic Infrared and Raman Spectra, McGraw-Hill European chemistry series, London, New York, McGraw-Hill, 1972.

[14] W. Martens, R.L. Frost, J.T. Kloprogge, P.A. Williams, J. Raman Spectrosc. 34 (2003) 145-151.

[15] G. Renaudin, R. Segni, D. Mentel, J.-M. Nedelec, F. Leroux, C. Taviot-Gueho, J Adv. Concr. Technol. 5 (2007) 299-312.

[16] S.C.B. Myneni, S.J. Traina, G.A. Waychunas, T.J. Logan, Geochim. Cosmochim. Acta 62 (1998) 3499-3514. 